\title{
Variation of the Earth tide-seismicity compliance parameter during the recent seismic activity in Fthiotida, central Greece
}

\author{
Dimitrios N. Arabelos, Michael E. Contadakis ${ }^{\star}$, Georgios Vergos, Spyrous Spatalas
}

University of Thessaloniki, Department of Geodesy and Surveying, Thessaloniki, Greece

\author{
Article history \\ Received May 14, 2015; accepted January 12, 2016. \\ Subject classification: \\ Earth tides, Seismicity, Hi(stogram)Cum(ulating) method, Schuster test.
}

\begin{abstract}
Based on the results of our previous studies concerning the tidal triggering effect on the seismicity in Greece, we consider the confidence level of earthquake occurrence - tidal period accordance as an index of tectonic stress criticality, associated with earthquake occurrence. Then, we investigate whether the recent increase in the seismic activity at Fthiotida in Greek mainland indicates faulting maturity and the possible production a stronger earthquake. In this paper we present the results of this investigation.
\end{abstract}

\section{Introduction}

Recent analyses on the problem of tidal triggering on earthquakes indicate that this effect is manifested [Heaton 1982, Rydelek et al. 1992, Tsuruoka et al. 1995, Vidale et al. 1998, Wilcock 2001, Tanaka et al. 2002, Tolstoy et al. 2002, Tanaka et al. 2006, Cadicheanu et al. 2007, Stroup et al. 2007]. In these studies, not only tidal triggering at the global [Tanaka et al. 2002] and local [Tanaka et al. 2006, Cadicheanu et al. 2007, Contadakis et al. 2012] scales was found. In addition, in the last three studies, an increase in the reliability of the tidalearthquake occurrence correlation was shown to be a precursory phenomenon for strong earthquakes. In the frame to this international effort, applying the Hist(ogram)Cum(ullating) method [van Ruymbecke et al. 2007], we have analyzed the series of the earthquakes occurred in the last 50 years in seismic active areas of Greece. These areas are: (a) the Mygdonian Basin [Contadakis et al. 2009], (b) the Ionian Islands [Contadakis et al. 2012], (c) the Hellenic Arc [Vergos et al. 2015] and (d) the Santorini [Contadakis et al. 2013]. The result of the analysis for all the areas indicate that the monthly variation of the earthquake frequency of is in accordance with the period of the tidal lunar monthly and semi-monthly (Mm and Mf) variations. Similarly, the same happens with the corresponding daily variations of the earthquake frequency with the diurnal luni-solar (K1) and semidiurnal lunar (M2) tidal variations. In addition the confidence level for the identification of such period accordance between earthquakes frequency and tidal period varies with seismic activity. The higher confidence level corresponds to time periods with stronger seismic activity. These results are in favor of a tidal triggering process on earthquakes when the stress in the focal area is near the critical level. Based on these results, we consider the confidence level of earthquake occurrence - tidal period accordance, $p$, as an index of tectonic stress criticality for earthquake occurrence. We call it "Earth tide-seismicity compliance parameter". Then we check on posterior weather the variation of the Earth tide-seismicity compliance parameter $p$, indicate the fault matureness in the case of the recent seismic activity in the prefecture of Fthiotida, central Greece. In this paper we present the results of this test.

\section{Seismicity in the broader area of Fthiotida}

On August 7, 2013, a magnitude 5.2 earthquake occurred in the prefecture of Fthiotida, central Greece followed by series of 18 earthquake with $M>4$ until April, 2013. The area is a well known tectonically active area in Greece. On April 20 and 27, 1894, two earthquakes of 6.4 and $6.6 \mathrm{M}_{\mathrm{L}}$ with more than 250 dead and hundreds of injured in human casualties and cased extensive damages. [Papazachos and Papazachou 2003, Ganas et al. 2006]. Figure 1 displays the area and the shocks with magnitudes greater than $3.5 \mathrm{M}_{\mathrm{L}}$ which occurred during 2013. In this figure the main faults of the area, as published by Ganas et al. [2006], are presented. Ganas et al. [2014], analyzing the aftershock sequence, conclude that the spatial distribution of the aftershock sequence points towards the reactivation of a $\mathrm{N} 70^{\circ} \pm 10^{\circ} \mathrm{E}$ striking normal fault at crustal depths between 8 and $13 \mathrm{~km}$. A NNW-SSE cross-section im- 


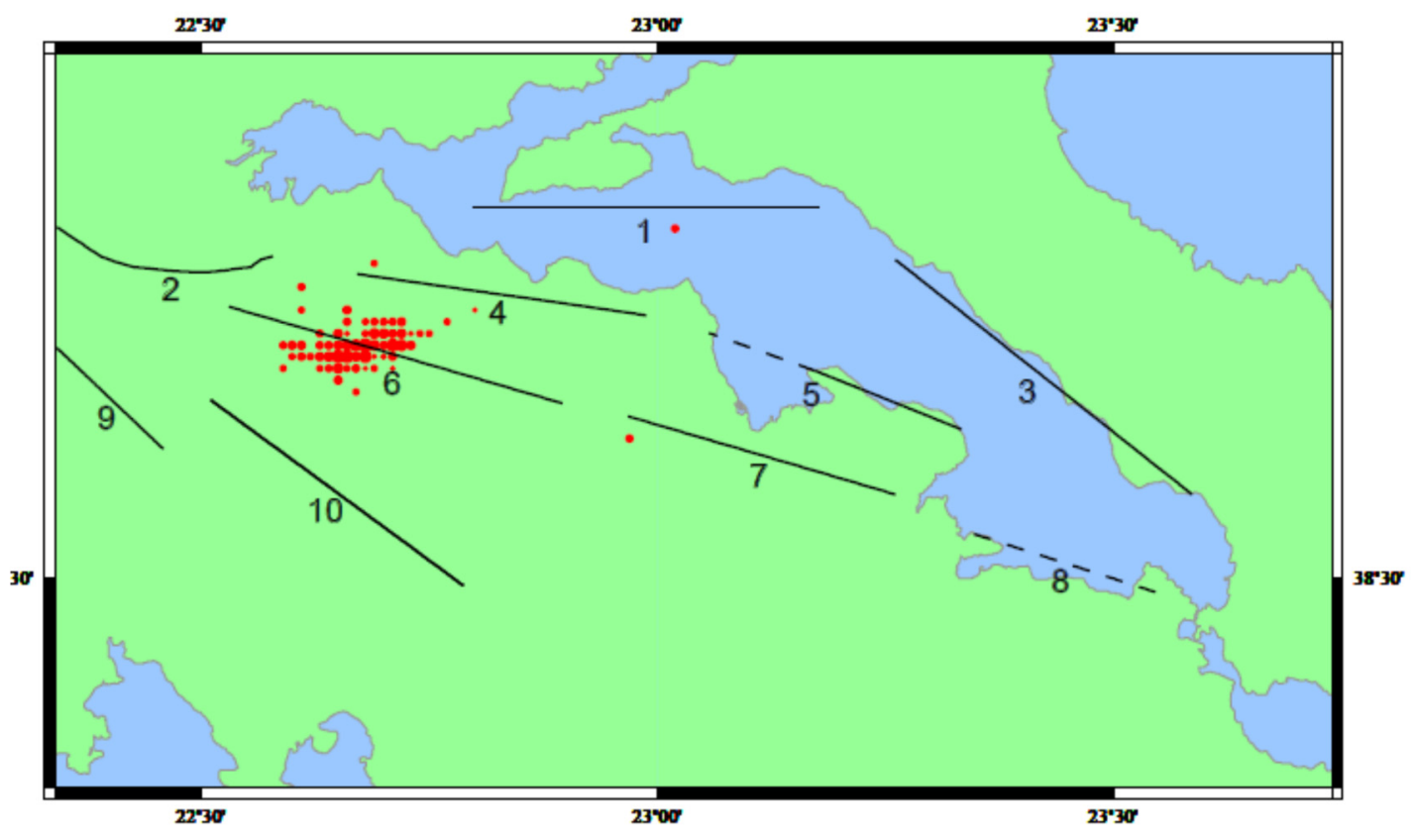

Figure 1. The seismic activity of 2013 in Fthiotida (shematic fault of the area; Ganas et al. [2006]). (1) Edipsos, (2) Sperchios, (3) Kadilli, (4,5) Kamena Vourla, (6) Kallidromon, $(7,8)$ Atalanti, $(9,10)$ Tithorea.

aged the activation of a steep, south dipping normal fault. They interpret the Kallidromon seismic sequence as release of extensional seismic strain on secondary steep faults inside the Fokida-Viotia crustal block.

Table 1 displays the earthquakes with magnitudes greater than $M=4$ that occurred in the area during 2013.

In addition a Seismic Electrical Signal (SES) activity, initiated on January 8, 2013, was recorded at a station of VAN Network, labeled LAM, in central Greece. Additional SES activities were recorded at LAM from

\begin{tabular}{|c|c|c|c|c|c|c|c|}
\hline & Date & Time & Distance from the nearest city & $\varphi$ degree & $\lambda$ degree & Depth $(\mathrm{km})$ & Magnitude \\
\hline 1 & $2013 / 12 / 11$ & $13: 00: 53$ & $17.4 \mathrm{~km} \mathrm{NW}$ of Lamia & 39.01 & 22.29 & 21 & 4.2 \\
\hline 2 & $2013 / 11 / 22$ & $15: 12: 03$ & $16.8 \mathrm{~km} \mathrm{~N}$ of Lamia & 39.05 & 22.41 & 21 & 4.2 \\
\hline 3 & $2013 / 11 / 12$ & $18: 09: 28$ & $31.2 \mathrm{~km}$ NNE of Atalanti & 38.92 & 23.10 & 17 & 4.8 \\
\hline 4 & $2013 / 09 / 20$ & 02:05:18 & $32.0 \mathrm{~km}$ NNE ofKorinthos & 38.18 & 23.13 & 23 & 4.4 \\
\hline 5 & $2013 / 09 / 17$ & $07: 39: 44$ & $24.0 \mathrm{~km} \mathrm{WNW}$ of Atalanti & 38.70 & 22.73 & 13 & 4.0 \\
\hline 6 & $2013 / 09 / 16$ & $15: 01: 14$ & $23.8 \mathrm{~km} \mathrm{WNW}$ of Atalanti & 38.72 & 22.74 & 17 & 4.9 \\
\hline 7 & $2013 / 09 / 16$ & $14: 42: 39$ & $24.0 \mathrm{~km} \mathrm{WNW}$ of Atalanti & 38.70 & 22.73 & 20 & 4.5 \\
\hline 8 & $2013 / 08 / 18$ & $16: 39: 21$ & $24.8 \mathrm{~km} \mathrm{WNW}$ of Atalanti & 38.70 & 22.72 & 13 & 4.0 \\
\hline 9 & $2013 / 08 / 18$ & $10: 42: 54$ & $24.8 \mathrm{~km} \mathrm{WNW}$ of Atalanti & 38.70 & 22.72 & 14 & 4.0 \\
\hline 10 & $2013 / 08 / 09$ & $13: 10: 10$ & $30.0 \mathrm{~km} \mathrm{SE}$ of Lamia & 38.69 & 22.65 & 17 & 4.7 \\
\hline 11 & $2013 / 08 / 09$ & $11: 49: 56$ & $28.0 \mathrm{~km} \mathrm{~W}$ of Atalanti & 38.69 & 22.68 & 9 & 4.6 \\
\hline 12 & $2013 / 08 / 09$ & $11: 49: 23$ & $25.7 \mathrm{~km} \mathrm{WNW}$ of Atalanti & 38.70 & 22.71 & 19 & 4.8 \\
\hline 13 & $2013 / 08 / 07$ & $13: 44: 32$ & $29.8 \mathrm{~km} \mathrm{~W}$ of Atalanti & 38.69 & 22.66 & 15 & 4.7 \\
\hline 14 & $2013 / 08 / 07$ & $09: 56: 35$ & $27.4 \mathrm{~km} \mathrm{WNW}$ of Atalanti & 38.70 & 22.69 & 14 & 4.0 \\
\hline 15 & $2013 / 08 / 07$ & 09:06:51 & $28.2 \mathrm{~km} \mathrm{~W}$ of Atalanti & 38.70 & 22.68 & 8 & 5.2 \\
\hline 16 & $2013 / 08 / 07$ & $09: 02: 45$ & $29.1 \mathrm{~km} \mathrm{~W}$ of Atalanti & 38.70 & 22.67 & 14 & 4.3 \\
\hline 17 & $2013 / 04 / 28$ & $04: 49: 55$ & $14.7 \mathrm{~km}$ E of Aegion & 38.26 & 22.25 & 55 & 4.2 \\
\hline 18 & $2013 / 01 / 30$ & $04: 27: 25$ & $35.2 \mathrm{~km}$ ENE of Atalanti & 38.78 & 23.37 & 22 & 4.0 \\
\hline
\end{tabular}

Table 1. Earthquakes with $\mathrm{M}_{\mathrm{L}}>4.0$, in the study area of Figure 1. 
March 31 to April 11, 2013 [Sarlis et al. 2015]. This indicate that the area of central Greece enter to a tectonically critical stage. Then Sarlis et al. [2015] analyzed the earthquake sequence from that moment on up to August 12, 2013, in the natural time domain, using the procedure developed in Varotsos et al. [2005]. They found that the probability $\operatorname{Prob}(\kappa 1)$ of the $\kappa 1$ values of seismicity in the area of the earthquake of August 7, maximized at $\kappa 1=0.070$ at times between 13:10 UT and 19:49 UT of August 9, 2013, exhibiting magnitude threshold invariance in the broad magnitude range $M_{\text {thres }}=2.6$ to 3.6 (which suggests that the system approaches the critical point).

In conclusion, different approaches indicate that the area of Fthiotida is found in tectonic excitation.

For this area we apply the Hi(stogram)Cum(ulating)method in order to see if tidal triggering effect is been detected and if this effect is better traced in the period of the increased microseismicity i.e. the years 2011 - February of 2012.

In our analysis we use the seismological data of the earthquake catalogue of NOA (http: / / www.gein. noa.gr). The set of data consist of a series of 33281 shallow and 769 of intermediate depth earthquakes with $\mathrm{M}_{\mathrm{L}}$ ranging from 0.2 to 6.3 , occurred within the time interval from January 1964 to December 2013, in an area bounded by $38^{\circ} \leq \varphi \leq 39^{\circ}$ and $21^{\circ} \leq \lambda \leq 23^{\circ}$.

However, since 1964 the network of NOA subjected three main upgrades. (1) In 1995 the instrumentation and processing passed from analog-to-digital mode. (2) Gradually from the end of 2007 to 2011 developed the Hellenic Unified Seismological Network (HUSN), which combined the NOA network to three university networks (Athens, Patras, and Thessaloniki), and (3) in early 2011 the magnitude determination software has been upgraded [Chouliaras 2009, Chouliaras et al. 2013, Mignan and Chouliaras 2014]. As a result the completeness magnitude Mc of the NOA catalogue varies. Thus in order to realize if the development of

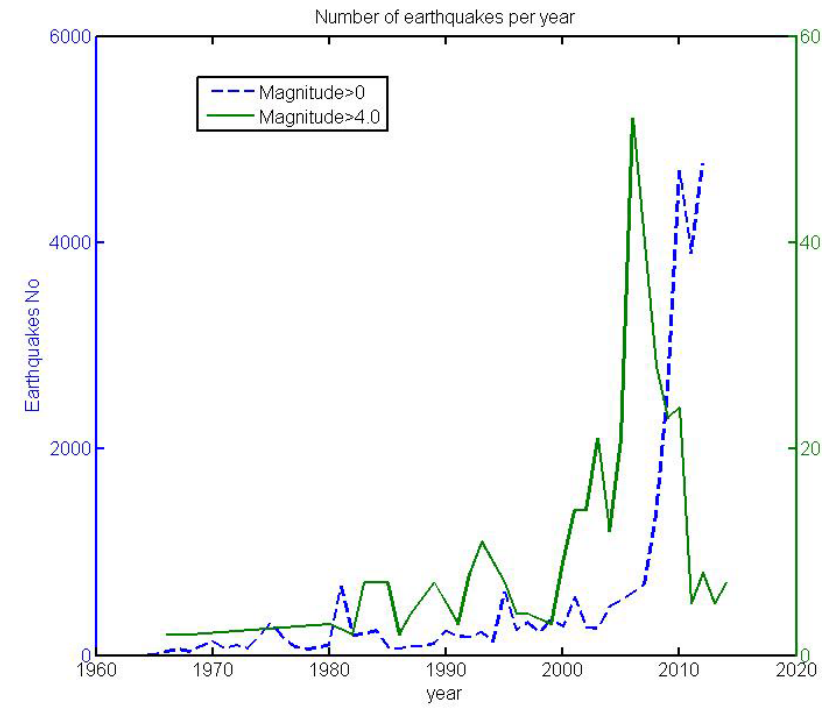

Figure 2. The development of the seismicity in the selected area from 1964 until December of 2013 using both the original and the one with $\mathrm{M}>2.8$

the seismicity from 1964 up to 2014 is real and not artificial due to the variation of the magnitude completeness $\mathrm{Mc}$, we pick earthquakes with magnitudes $\mathrm{M}>\mathrm{Mc}$ of the most insensitive period, from the catalogue. According to Mignan and Chouliaras [2014] recommendation, for statistical studies $\mathrm{Mc}=\mathrm{M}_{\mathrm{BMC}}+3 \sigma$, where $\mathrm{M}_{\mathrm{BMC}}$ and $\sigma$ are the Bayesian Magnitude Completeness and the respective standard deviation. From the respective maps (Figures 3 and 4 ) of the paper of Mignan and Chouliaras [2014] we get $M_{B M}=2.5$ and $\sigma=0.1$ for the most insensitive period, which is 1964-1995, for Fthiotida. Thus the magnitude completeness is $\mathrm{Mc}=2.8$. The resulting development of the seismicity is similar to the seismicity development shown by the original catalogue. We conclude that the variation of the seismicity, shown by the original catalogue, is real. Figure 2 displaces the development of the seismicity in the area from 1964, using both catalogues, the original and the one with $M>2.8$. It is seen that the number of earthquakes is greatly increased since 2009. Finally, it

\begin{tabular}{|c|c|c|c|c|}
\hline Symbol & $\begin{array}{l}\text { Period } T \\
\quad(\min )\end{array}$ & Signal/noise & $\begin{array}{l}\text { Amplitude } \\
\left(\mathrm{nms}^{-2}\right)\end{array}$ & Origin \\
\hline $\mathrm{K} 1$ & 1436 & 525.1 & 487.840 & $\begin{array}{l}\text { Lunar and solar } \\
\text { declination wave }\end{array}$ \\
\hline O1 & 1549 & 379.7 & 352.816 & $\begin{array}{c}\text { Lunar } \\
\text { principal wave }\end{array}$ \\
\hline M2 & 745 & 1208.5 & 510.350 & $\begin{array}{c}\text { Lunar } \\
\text { principal wave }\end{array}$ \\
\hline $\mathrm{S} 2$ & 720 & 564.5 & 238.393 & $\begin{array}{c}\text { Solar } \\
\text { principal wave }\end{array}$ \\
\hline
\end{tabular}

Table 2. The strongest components of Earth tides in Thessaloniki. 
should be noted that only for the years 1964 and 1965 the total number of earthquakes was less than 30 , rendering the results of Shuster's test doubtful.

\section{Tidal effect}

Tidal effects on a rigid Earth can be computed theoretically from the ephemerides of the Moon, the Sun and the planets. The Earth tides are the combined effect of the mentioned celestial bodies and the reaction of the solid Earth (like an elastic body) to the tidal forces. The ocean tides follow the law of hydrodynamics, with strong disturbances affecting adjacent seas, so that the ocean loading effect has to be taken into account. Earth tides are discussed extensively in Melchior [1983], Baker [1984], Torge [2001].

The constituents of the Earth tides for the area of Thessaloniki were determined gravimetrically by Arabelos [2002]. Table 2 displays the strongest components of the Earth tides for Thessaloniki. Although the amplitude of the lunar tidal component M1 is equal 27.091 $\mathrm{nms}^{-2}$ (see Arabelos [2002], Table 3), i.e. it is much weaker than the listed components, we consider in addition the possible effect of this constituent by means of the lunar synodic month (i.e. period from new moon to new moon which is $29^{\mathrm{d}} .530589$ ) as well as by lunar anomalistic month (i.e. time period between two successive passages of the moon from perigee which is $\left.27^{\mathrm{d}} .554551\right)$.

Table 3 displays the actual ocean corrected tidal parameters of $\mathrm{O} 1$ and M2 for Sofia, Instabul and Thessaloniki, and the corresponding values from the model of Wahr-Dehant-Zschau [Dehant 1987, Dehant and Zchau 1989], expressing the dependency of the tidal parameters on the latitude. As it is shown from Table 3 the amplitude factors of the principal O1 and M2 tidal constituents agree within their error of estimation with the model.

For the latitude of $38^{\circ}$ which is the mean latitude of the area under consideration, the extrapolated model amplitude factors for $\mathrm{O} 1$ and $\mathrm{M} 2$ are equal to 1.156 and 1.158 respectively. Consequently, the amplitudes of $\mathrm{O} 1$ and M2 might be changed to about 408 and $591 \mathrm{nms}^{-2}$ respectively, which are very close to the amplitudes observed in the tidal station of Thessaloniki. However, this estimation does not take into account the actual elastic properties of the lithosphere in the Ionian zone.

\section{Method of analysis}

As we have done in previous studies [Contadakis et al. 2009, Contadakis et al. 2012, Vergos et al. 2015], in order to check the possible correlation between Earth tides and earthquake occurrence we investigate the time of occurrence of each earthquake in relation to the sinusoidal variation of Earth tides and investigate the possible correlation of the time distribution of the earthquake events with Earth tides variation. Since the periods of the Earth tides component are very well known and quite accurately predictable in the local coordination system we assign a unique phase angle within the period of variation of a particular tidal component, for which the effect of earthquake triggering is under investigation, with the simple relation:

$\phi_{i}=\left\{\left[\left(t_{i}-t_{0}\right) / T_{d}\right]\right\}-\operatorname{int}\left\{\left[\left(t_{i}-t_{0}\right) / T_{d}\right]\right\} \times 360$

where $\phi_{i}=$ the phase angle of the time occurrence of the $i$ earthquake in degrees,

$t_{i}=$ the time of occurrence of the i earthquake in Modified Julian Days (MJD),

$t_{0}=$ the epoch we have chosen in MJD,

$T_{d}=$ the period of the particular tidal component in Julian Days.

We choose as epoch $t_{o}$, i.e. as reference date, the time of the upper culmination in Thessaloniki of the new moon of January 7, 1989, which has MJD= 47533.8947453704. Thus the calculated phase angle for all the periods under study has 0 phase angle at the maximum of the corresponding tidal component (of course $\mathrm{M} 2$ and $\mathrm{S} 2$ has an upper culmination maximum every two cycles). As far as the monthly anomalistic moon concern the corresponding epoch $t_{0}$ is January 14, 1989, which has MJD = 47541.28492.

\begin{tabular}{|c|c|c|c|c|c|c|}
\hline & \multicolumn{2}{|c|}{ Sofia $\left(\right.$ latitude $=42.71^{\circ}$ ) } & \multicolumn{2}{|c|}{ Istanbul $\left(\right.$ latitude $\left.=41.07^{\circ}\right)$} & \multicolumn{2}{|c|}{ Thessaloniki $\left(\right.$ latitude $\left.=40.63^{\circ}\right)$} \\
\hline & $\begin{array}{l}\text { Amplitude } \\
\text { factor }\end{array}$ & $\begin{array}{l}\text { Phase } \\
\text { degree }\end{array}$ & $\begin{array}{l}\text { Amplitude } \\
\text { factor }\end{array}$ & $\begin{array}{l}\text { Phase } \\
\text { degree }\end{array}$ & $\begin{array}{l}\text { Amplitude nm } \\
\text { factor }\end{array}$ & $\begin{array}{l}\text { Phase } \\
\text { degree }\end{array}$ \\
\hline O1 & $1.1493 \pm 0.0014$ & $-.1590 \pm .060$ & $1.1564 \pm 0.0035$ & $-.281 \pm 0.174$ & $1.1536 \pm 0.003$ & $-.201 \pm 0.151$ \\
\hline Model & 1.1540 & -0.2 & 1.1542 & -0.2 & 1.1543 & -0.2 \\
\hline M2 & $1.1541 \pm 0.0005$ & $-.207 \pm 0.026$ & $1.1587 \pm 0.0011$ & $-.039 \pm 0.026$ & $1.1639 \pm 0.001$ & $-.195 \pm 0.001$ \\
\hline Model & 1.1541 & -0.2 & 1.1583 & -0.2 & 1.1583 & -0.2 \\
\hline
\end{tabular}

Table 3. Ocean corrected parameters of $\mathrm{O} 1$ and $\mathrm{M} 2$ in 3 neighboring stations. 
We separate the whole period in 12 bins of $30^{\circ}$ and stack every event according to its phase angle in the proper bin. Thus we construct a Cumulating Histogram of earthquake events for the tidal period under study.

In order to check the compliance of the earthquake frequency distribution periods with the tidal periods we use the well known Shuster's test [Shuster 1897; see also Tanaka et al. 2002, Tanaka et al. 2006, Cadicheanu et al. 2007]. In Shuster's test, each earthquake is represented by a unit length vector in the direction of the assigned phase angle $\tilde{a}_{i}$. The vectorial sum $D$ is defined as:

$$
D^{2}=\left(\sum_{i=1}^{N} \cos a_{i}\right)^{2}+\left(\sum_{i=1}^{N} \sin a_{i}\right)^{2}
$$

where $N$ is the number of earthquakes. When $\alpha_{i}$ is distributed randomly, the probability to be the length of a vectorial sum equal or larger than $D$ is given by the equation:

$$
p=\exp \left[-\frac{D^{2}}{N}\right]
$$

Thus, $p<5 \%$ represents the significance level at which the null hypothesis that the earthquakes occurred randomly with respect to the tidal phase is rejected. This means that the smaller the $p$ is the greater the confidence level of the results of the Cumulating Histograms is. Finally it should be noted that the total number of the shocks for each year is greater than 30 for all the years since 1966. This means that the normal distribution approach on which Shuster test is based is valid for all the years since 1966.

\section{Results}

Figures 3 to 8 display the Cumulating Histogram for the 6291 earthquakes which occurred in the time interval from January 1st, 2013, to December 31, 2013. These figures correspond to the tidal periods of: Anomalistic Monthly period (i.e. time period between two successive passages of the moon from perigee which is $27^{\mathrm{d}}$.554551) (Figure 3), Synodic Monthy period (i.e. period from new moon to new moon which is $29^{\mathrm{d}} .530589$ ) (Figure 4), Diurnal luni-solar constituents K1 (Figure 5), Diurnal luni-solar constituent O1 (Figure 6), Semidiurnal solar constituents S2 (Figure 7), and Semi-diurnal lunar constituent (Figure 8), for the last year of the 50-year analyzed data, i.e. 2013. It is obvious that there is a perfect compliance of tidal and earthquake occurance distribution for Monthly Anomalistic and Synodic period, Diurnal luni-solar K1 and Semi-diurnal solar S2 periods and a smaller compliance for the Diurnal lunisolar O1 and Semidiurnal lunar period. This is shown in Table 4. This table displays the corresponding confi-

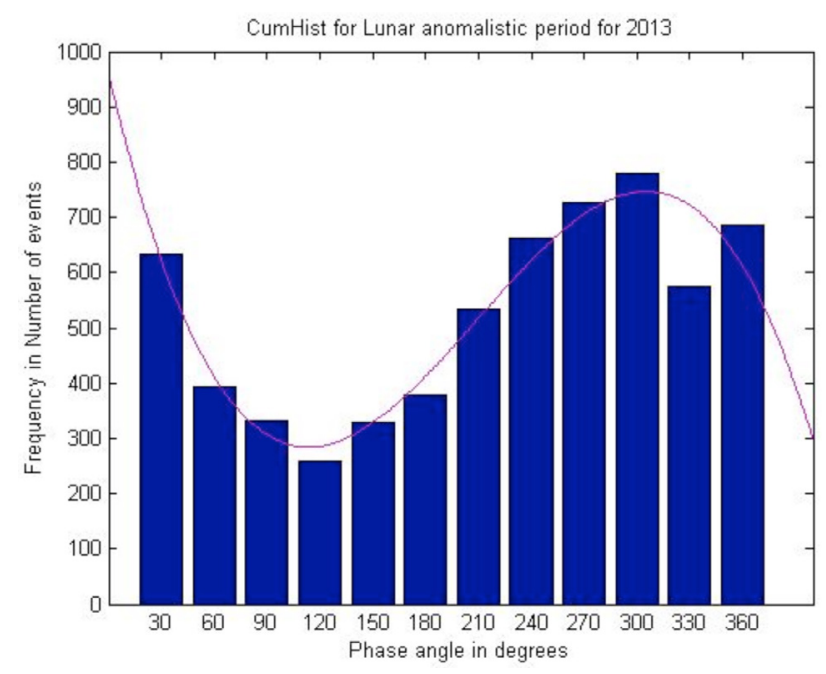

Figure 3. Hist(ogram)Cum(mulating) for the Anomalistic Monthly period for 2013 .

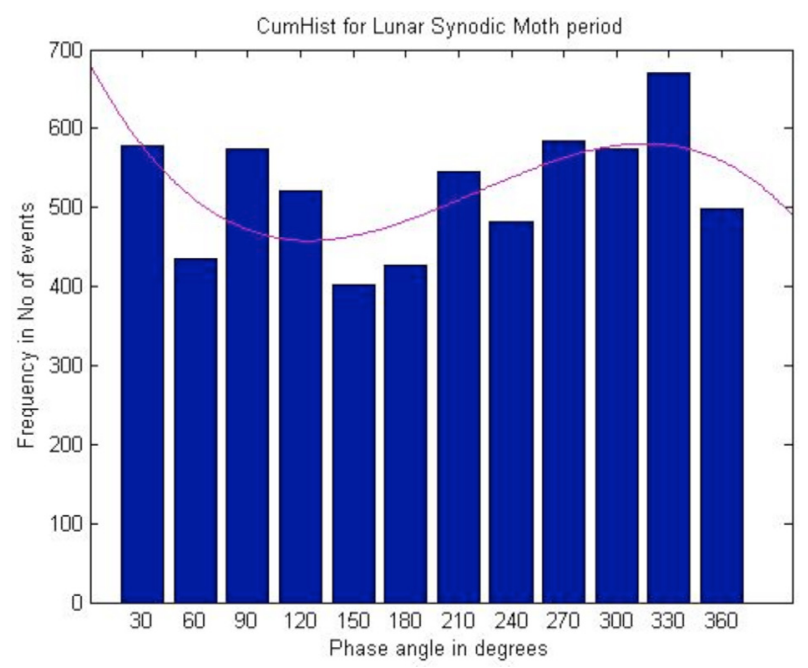

Figure 4. Hist(ogram)Cum(mulating) for the Synodic Monthly period for 2013.

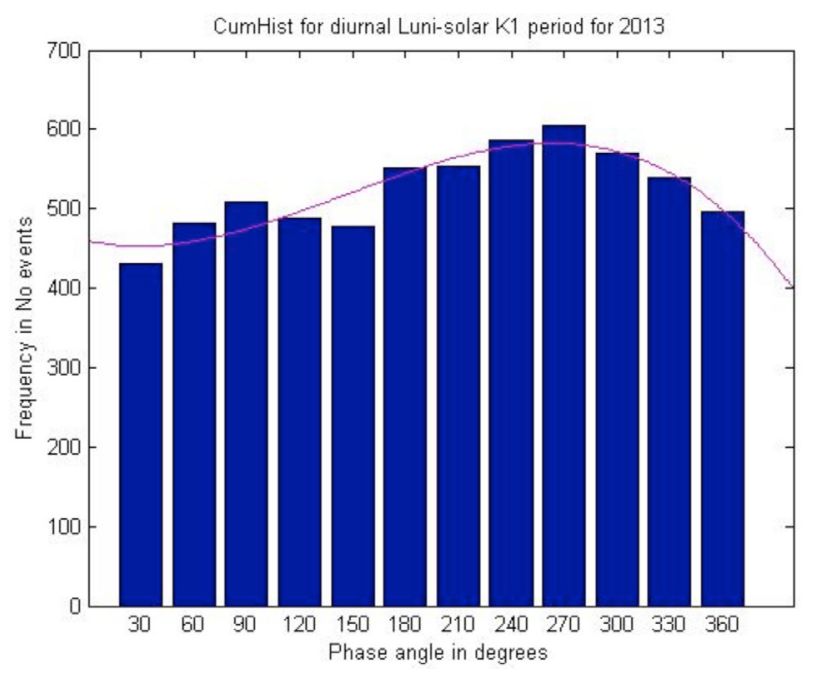

Figure 5. Hist(ogram)Cum(mulating) for the Luni-Solar K1 period for 2013 


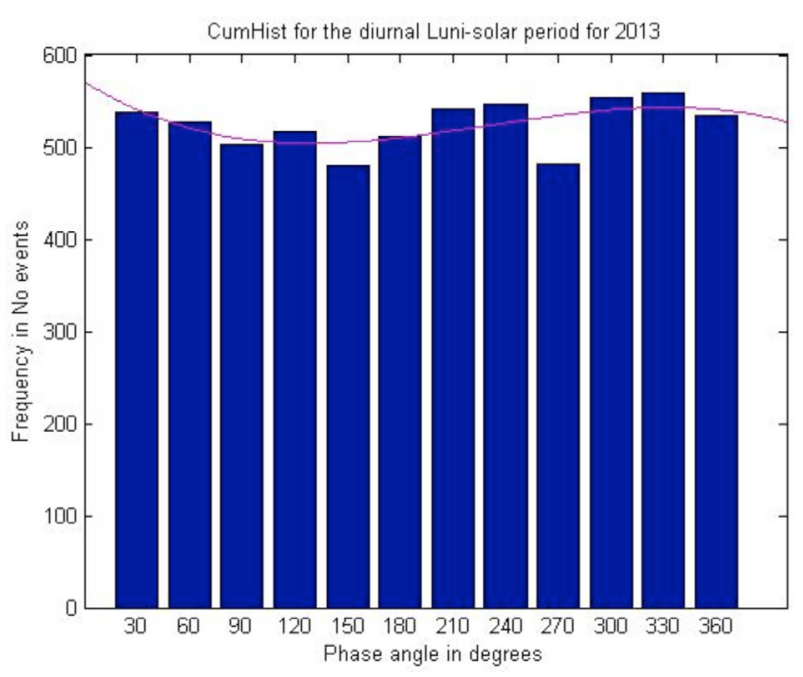

Figure 6. Hist(ogram)Cum(mulating) for the Luni-Solar O1 period for 2013.

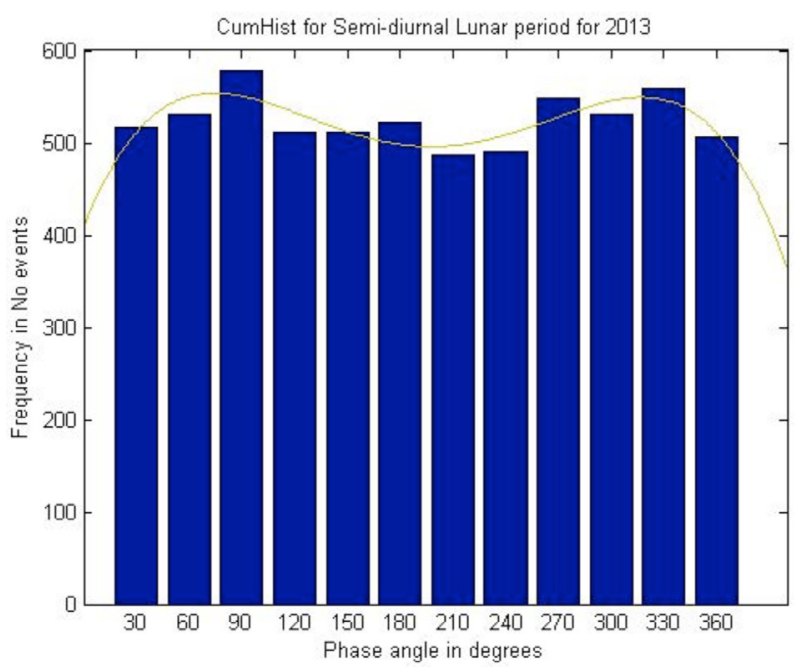

Figure 8. Hist(ogram)Cum(mulating) for the semi diurnal Lunar M2 period for 2013.

dence levels for all six tidal components for 2013 together with the same quantities for a year of low seismic activity, i.e. 1994 and the mean confidence levels for the 50 years. Year 1994 was a year with apparently smaller seismic activity than 2013.

Table 4 displays the confidence level of earthquake-Earth tide correlation for all earthquakes of the

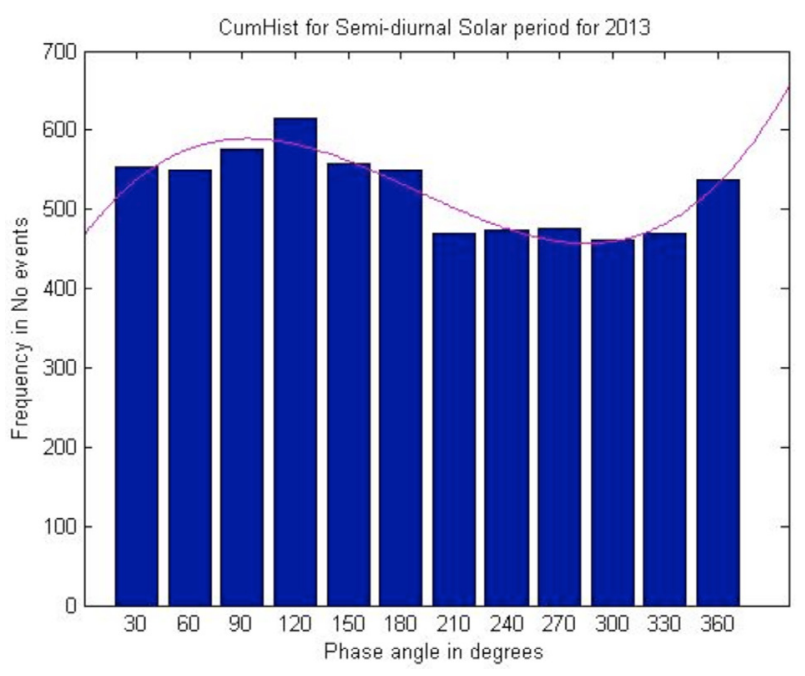

Figure 7. Cumulation Histogram for the semi diurnal Solar S2 period for 2013

broader area of Fthiotida for the year 2013. In comparison the Mean values of the confidence levels for the last fifty years as well as those for the year 1994, a relatively quiet seismically year. This Table indicates that the confidence level of the compliance of earthquake frequency distribution over the tidal period is very sensitive to the seismicity of the area. This is also shown in Figures 9 to 14. These figures display the variation of the confidence level parameter in the time period 1964 to 2013 together with the earthquakes occurrence for each year. Finally it has to be understood that the confidence level parameter $p$ indicate that the tectonic stress in the area has reached a critical point. This also has been found by Sarlis et al. [2015]. The magnitude of the potential earthquake depends on the tectonic morphology in the stress regime and seismic history of the area.

The high confidence level of the monthly tidal components, despite their small intensity, may indicate that they provide in general favourable conditions for the action of the much stronger tidal components $\mathrm{K} 1$ and $\mathrm{M} 2$. In this point we may refer to the fact that the monthly tidal barometric variations are quite sensitive to the seismic activity [Arabelos et al. 2008]. Perhaps this peculiar coincidence merits further investigation.

\begin{tabular}{ccccccc}
\hline & MAnom. & MSynod & K1 & O1 & S2 & M2 \\
\hline Mean & 0.172 & 0.182 & 0.387 & 0.420 & 0.306 & 0.435 \\
1994 & 0.971 & 0.481 & 0.470 & 0.791 & 0.816 & 0.812 \\
2013 & 0.000 & 0.000 & 0.000 & 0.101 & 0.000 & 0.159 \\
\hline
\end{tabular}

Table 4. The confidence level of the correlation between earthquake and Earth tide for all earthquakes of the broader area of Fthiotida for 2013 in comparison to the corresponding mean of the last fifty years as well as those of 1994 . 


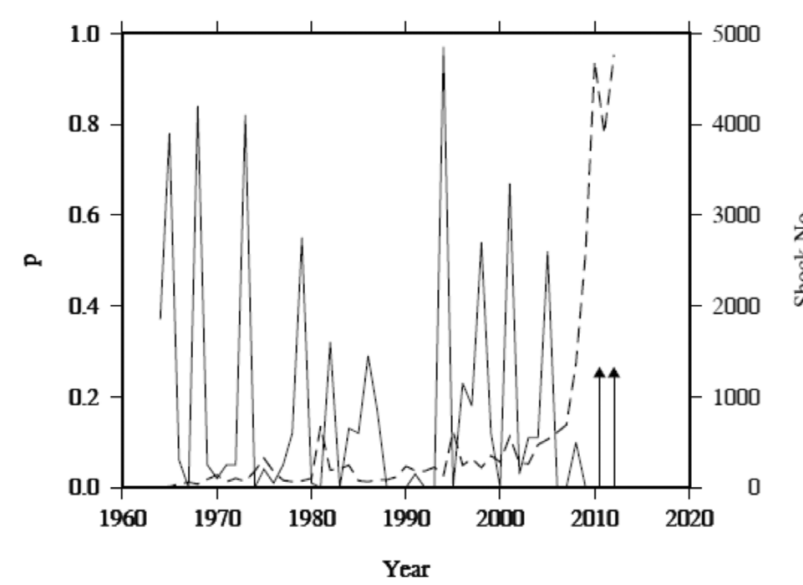

Figure 9. The confidence level parameter $p$ between Seismicity and Tidal Anomalistic Monthly period. Arrows indicate the $5.2 \mathrm{M}_{\mathrm{L}}$ earthquakes at Aegion on 2010 and Fthiotida on 2013.

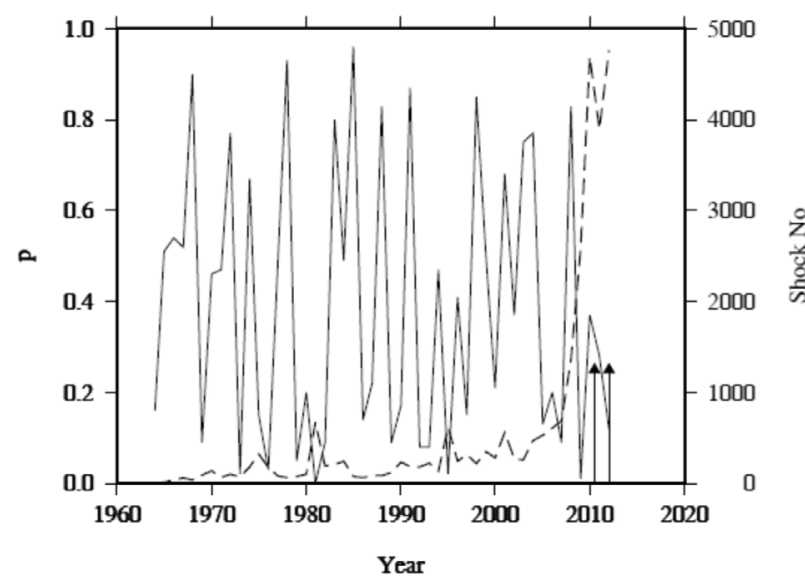

Figure 11. The confidence level parameter $p$ between Seismicity and diurnal Tidal Luni-Solar K1 period. Arrows indicate the $5.2 \mathrm{M}_{\mathrm{L}}$ earthquakes at Aegion on 2010 and Fthiotida on 2013.

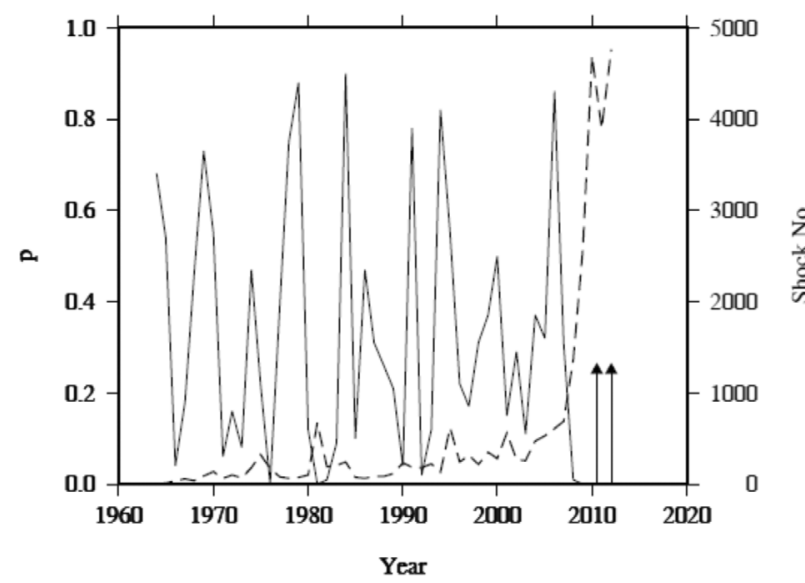

Figure 13. The confidence level parameter $p$ between Seismicity and Tidal semi diurnal Solar S2 period. Arrows indicate the $5.2 \mathrm{M}_{\mathrm{L}}$ earthquakes at Aegion on 2010 and Fthiotida on 2013.

\section{Conclusions}

In this paper we investigate the tidal triggering evidence on the earthquakes of the area of Fthiotida in Greece. The result of our analysis using the HiCum

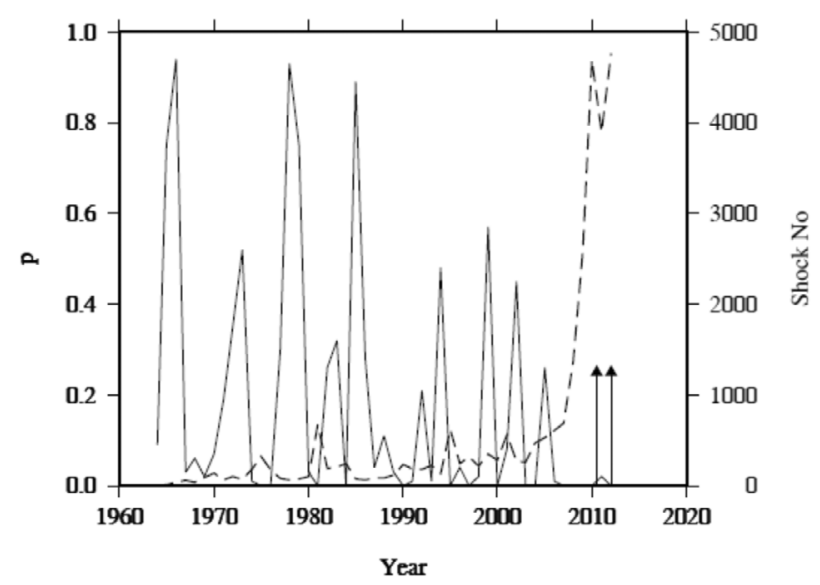

Figure 10. The confidence level parameter $p$ between Seismicity and Tidal Synodic Monthly period. Arrows indicate the $5.2 \mathrm{M}_{\mathrm{L}}$ earthquakes at Aegion on 2010 and Fthiotida on 2013.

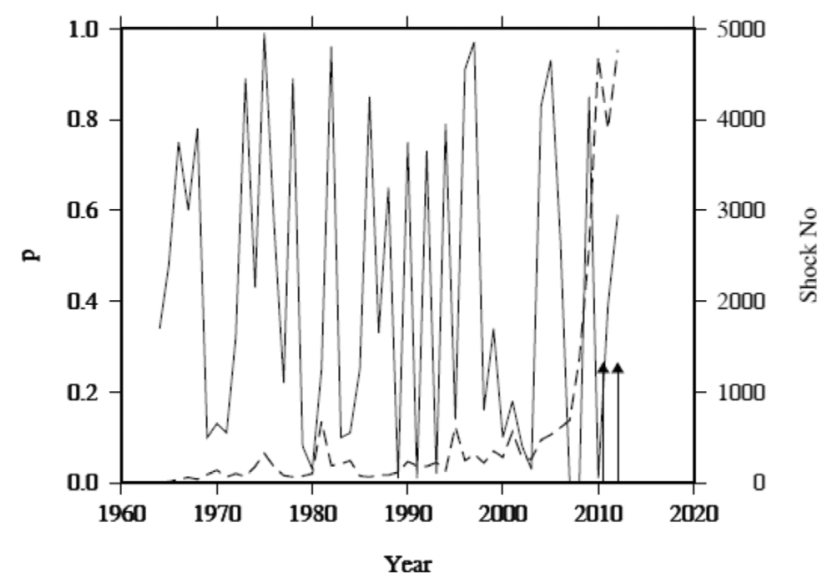

Figure 12. The confidence level parameter $p$ between Seismicity and Tidal diurnal Luni-Solar O1 period. Arrows indicate the $5.2 \mathrm{M}_{\mathrm{L}}$ earthquakes at Aegion on 2010 and Fthiotida on 2013.

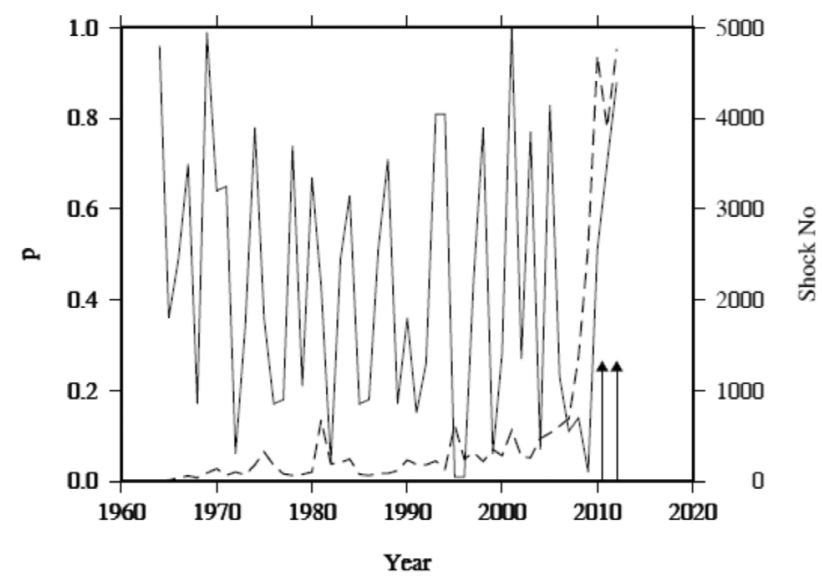

Figure 14. The confidence level parameter $p$ between Seismicity and Tidal semi diurnal Lunar M2 period. Arrows indicate the 5.2 $\mathrm{M}_{\mathrm{L}}$ earthquakes at Aegion on 2010 and Fthiotida on 2013.

method, indicate that the monthly variation of the frequencies of earthquake occurrence is in accordance with the period of the tidal lunar monthly $(\mathrm{Mm})$ variations. The same happens with the corresponding diurnal and 
semi-diurnal variations of the frequencies of earthquake occurrence with the diurnal (K1), (O1) and semi-diurnal solar (S2) and semidiurnal lunar (M2) tidal variations. The confidence level of the Tidal-Earthquake frequency period compliance is very sensitive to the seismicity of the area and we call it Tidal-Earthquake frequency compliance parameter. We suggest that this parameter may be used in earthquake risk assessment.

\section{References}

Arabelos, D. (2002). Comparison of Earth-tide parameters over a large latitude difference, Geophys. J. Int. (Research Note), 151, 950-956.

Arabelos, D.N., G. Asteriadis, A. Bloutsos, M.E. Contadakis and S.D. Spatalas (2008). Correlation between seismisity and barometric tidal exalting, Nat. Hazards Earth Syst. Sci., 8, 1129-1137.

Baker, T.F. (1984). Tidal determination of the Earth, Sci. Progr., Oxford, 69, 197-233.

Cadicheanu, N., M. van Ruymbeke and P. Zhu (2007). Tidal triggering evidence of intermediate depth earthquakes in Vrancea zone (Romania), NHESS, 7 , 733-740.

Chouliaras, G. (2009). Investigating the earthquake catalog of the National Observatory of Athens, Nat. Hazards Earth Syst. Sci., 9, 905-912.

Chouliaras, G., N.S. Melis, G. Drakatos and K. Makropoulos (2013). Operational network improvements and increased reporting in the NOA (Greece) seismicity catalog, Adv. Geosci., 36, 7-9.

Contadakis, M.E., D.N. Arabelos and S. Spatalas (2009). Evidence for tidal triggering on the shallow earthquakes of the seismic area of Mygdonia basin, North Greece, In: D. Arabelos, M.E. Contadakis, C. Kaltsikis and I. Tziavos (eds.), Terrestrial and Stellar Environment, Ziti Publishing Thessaloniki, Greece, 223-235.

Contadakis, M.E., D.N. Arabelos and S.D. Spatalas (2012). Evidence for tidal triggering for the earthquakes of the Ionian geological zone, Greece, Annals of Geophysics, 55 (1), 73-81.

Contadakis, M.E., D.N. Arabelos and G. Vergos (2013). Testing the recent Santorini seismic activity for possible tidal triggering effect, GA. EGU2013-8358.

Dehant, V. (1987). Tidal parameters for the inelastic Earth, Phys. Earth Planet Inter., 49, 97-116.

Dehant, V., and J. Zschau (1989). The effect of mantle inelasticity on tidal gravity: a comparison between the spherical and the elliptical Earth model, Geophys. J. Int., 97, 549-555.

Ganas, A., E. Sokos, A. Agalos, G. Leontakianakos and S. Pavlides (2006). Coulomb stress triggering of earthquakes along the Atalanti Fault, central Greece: Two
April 1894 M6+ events and stress change patterns, Tectonophysics, 420, 357-369.

Ganas, A., V. Karastathis, A. Moshou, S. Valkaniotis, E. Mouzakiotis and G. Papathanassiou (2014). Aftershock relocation and frequency-size distribution, stress inversionand seismotectonic setting of the 7 August $2013 \mathrm{M}=5.4$ earthquake in Kallidromon Mountain, central Greece, Tectonophysics, 617, 101-113

Heaton, T.H. (1982). Tidal triggering of earthquakes, B. Seismol. Soc. Am., 72, 2181-2200.

Melchior, P. (1983). The Tides of the Planet Eath, Pergamon Press, New York.

Mignan, A., and G. Chouliaras (2014). 50 Years of Seismic Network Performance in Greece (1964-2013): Spatiotemporal Evolution of the Completeness Magnitude, Seismol. Res. Lett., 85 (3), 657-667.

Papazachos, B.C., and C.B. Papazachou (2003). The Earthquakes of Greece, Ziti Publishing, Thessaloniki, in Greek.

Rydelek, P.A., I.S. Sacks and R. Scarpa (1992). On tidal triggering of earthquakes at Campi Flegrei, Italy, Geophys. J. Int., 109, 125-137.

Sarlis, N.V., P.A. Varotsos and E.S. Skordas (2015). Fluctuation theorem and natural time analysis; http:// arxiv.org/abs/1301.7634v4.

Schuster, A. (1897). On lunar and solar periodicities of earthquakes, Proc. R. Soc. Lond., 61, 455-465.

Stroup, D.F., D.R. Bohnenstiehl, M. Tolstoy, F. Waldhauser and R.T. Weekly (2007). Pulse of the seafloor: Tidal triggering of micro earthquakes at $9^{\circ} 50^{\prime} \mathrm{N}$ East Pacific Rise, Geophys. Res. Lett., 34, L15301.

Tanaka, S., M. Ohtake and H. Sato (2002). Evidence for tidal triggering of earthquakes as revealed from statistical analysis of global data, J. Geophys. Res., 107 (5B10), 2211.

Tanaka, S., H. Sato, S. Matsumura and M. Ohtake (2006). Tidal triggering of earthquakes in the subducting Philipine Sea plate beneath the locked zone of the plate interface in Tokai region, Japan, Tectonophysics, 417, 69-80.

Tolstoy, M., F.L. Vernon, J.A. Orcutt and F.K. Wyatt (2002). Breathingof the seafloor: tidal correlations of seismicity at Axial volcano, Geology, 30, 503-506.

Torge, W. (2001). Geodesy, 3rd ed., Walter de Gruyter, Berlin-New York.

Tsuruoka, H., M. Ohtake and H. Sato (1995). Statistical test of the tidaltriggering of earthquakes: contribution of the ocean tide loadingeffect, Geophys. J. Int., 122, 183-194.

van Ruymbeke, M., P. Zhu, N. Cadicheanu and S. Naslin (2007). VeryWeak Signals (VWS) detected by stacking method according todifferent astronomical pe- 
riodicities (HiCum), Nat. Hazards Earth Syst. Sci., 7, 651-656.

Varotsos, P.A., N.V. Sarlis, H.K. Tanaka and E.S. Skordas (2005). Similarity of fluctuations in correlated systems: The case of seismicity, Physical Review E 72, 041103.

Vergos, G., D.N. Arabelos and M.E. Contadakis (2015). Evidence for Tidal triggering on the earthquakes of the Hellenic Arc, Greece, Phys. Chem. Earth, 85-86, 210-215.

Vidale, J.E., D.C. Agnew, M.J.S. Johnston and D.H. Oppenheimer (1998). Absence of earthquake correlation with Earth tides: an indication of high preseismic fault stress rate, J. Geophys. Res., 103, 24567-24572.

Wilcock, W.S.D. (2001). Tidal triggering of microearthquakes on the Juande Fuca Ridge, Geophys. Res. Lett., 28, 3999-4002.

${ }^{\star}$ Corresponding author: Michael E. Contadakis,

University of Thessaloniki, Department of Geodesy and Surveying, Thessaloniki, Greece; email: kodadaki@eng.auth.gr.

C) 2016 by the Istituto Nazionale di Geofisica e Vulcanologia. All rights reserved. 